\title{
Patient preferences in severe COPD and asthma: a comprehensive literature review
}

This article was published in the following Dove Press journal:

International Journal of COPD

8 April 2015

Number of times this article has been viewed

\author{
Basil G Bereza' \\ Anders Troelsgaard \\ Nielsen ${ }^{2}$ \\ Sverrir Valgardsson ${ }^{3}$ \\ Michiel EH Hemels ${ }^{2}$ \\ Thomas R Einarson' \\ 'Leslie Dan Faculty of Pharmacy, \\ University of Toronto, ON, Canada \\ 2Janssen A/S, Birkerød, Denmark; \\ 3 Janssen-Cilag A/S, Oslo, Norway
}

Background: Management of chronic incurable diseases such as chronic obstructive pulmonary disease (COPD) and asthma is difficult. Incorporation of patient preferences is widely encouraged.

Purpose: To summarize original research articles determining patient preference in moderateto-severe disease.

Methods: Acceptable articles consisted of original research determining preferences for any aspect of care in patients with COPD/asthma. The target population included those with severe disease; however, articles were accepted if they separated outcomes by severity or if the majority had at least moderate-to-severe disease. We also accepted simulation research based on scenarios describing situations involving moderate-to-severe disease that elicited preferences. Two reviewers searched Medline and Embase for articles published from the date of inception of the databases until the end of November 2014, with differences resolved through consensus discussion. Data were tabulated and analyzed descriptively.

Results: About 478 articles identified, 448 were rejected and 30 analyzed. There were 25 on COPD and five on asthma. Themes identified as most important in COPD were symptom relief (dyspnea/breathlessness), a positive patient-physician relationship, quality-of-life impairments, and information availability. Patients strongly preferred sponsors' inhalers. At end-of-life, 69\% preferred receiving CPR, 70\% wanted noninvasive, and 58\% invasive mechanical intervention. While patients with asthma preferred treatments that increased symptom-free days, they were willing to trade days without symptoms for a reduction in adverse events and greater convenience. Asthma patients were willing to pay for waking up once and not needing their inhaler over waking up once overnight and needing their inhaler.

Conclusion: Few studies have examined patient preference in these diseases. More research is needed to fill in knowledge gaps.

Keywords: autonomy, end-of-life care, convenience, satisfaction, willingness-to-pay

\section{Introduction}

Respiratory diseases affect a very large proportion of people in the world, imposing a tremendous burden in terms of morbidity, mortality, and cost. ${ }^{1}$ The World Health Organization $^{2}$ has estimated that almost 329 million people, or $4.77 \%$ of the world's population have chronic obstructive pulmonary disease (COPD). This disease affects males and females almost equally ( $4.85 \%$ for males and $4.69 \%$ for females). Another 334 million (4.85\%) have asthma, with females a little more affected than males (5.09\% females versus $4.61 \%$ males).

The impact of these diseases has been assessed by the World Health Organization in a series of publications. The Global Burden of Disease Study 2010 reported that COPD ranked \#3 leading cause of death in the world. In terms of years of life lost in the world, COPD ranked \#9 and asthma ranked \#42. Of the 52,769,700 deaths in $2010,2,899,900(5.5 \%)$ were due to COPD and another $345,700(0.7 \%)$ were as a
Correspondence: Thomas R Einarson Leslie Dan Faculty of Pharmacy, I 44 College Street, Room 674, Toronto, ON M5S 3M2, Canada Tel + I 4 I 69786989

Fax + | 4I 6978 I833

Email t.einarson@rogers.com 
result of asthma. ${ }^{3}$ According to another publication in that series, chronic respiratory diseases accounted for $4.7 \%$ of all disability adjusted life years (DALYs) in the world. COPD was responsible for two-thirds of that burden, ranking as the ninth leading cause of DALYs, while asthma accounted for about one-fifth of that burden and ranked 28th overall. ${ }^{4}$ Thus, these diseases are important for the health care system, patients, and their families.

Many authors have indicated that patient preference is an important factor to consider in the management of many diseases, including COPD and asthma. In fact, in the UK, the National Institute for Health and Care Excellence (NICE) has issued a guideline aimed at involving patients in decisions about their medications in an attempt to improve adherence rates. ${ }^{5}$ Furthermore, patient preference has become so important that it has led to the development of at least two new forms of clinical trial known as the patient preference trial. ${ }^{6-8}$

Researchers have determined that the burden of these diseases increases with their severity, while the quality of life decreases. ${ }^{9-11}$ Therefore, it is important to conduct assessments in the light of disease severity. Many different methods for categorizing severity have been published and used. Two widely accepted schemes are those for asthma developed by the Global Initiative for Asthma (GINA), ${ }^{12}$ and for COPD by the Global Initiative for Chronic Obstructive Lung Disease (GOLD). ${ }^{13}$

A search of PubMed could locate no overviews of patient preference in either asthma or COPD in the last 5 years. Given the importance of these diseases and the issue of patient preference, this research was undertaken. The main goal was to summarize preferences of patients with moderate-to-severe asthma or COPD. We wished to identify aspects of care considered important to patients and determine unmet needs. Our intention was to provide an overview of the available information on this topic to indicate what is currently known, especially about the more severe forms of these diseases. Such information would be of value and could assist in care management, which is often less than optimal, especially in patients having severe disease.

\section{Methods}

This research was done with guidance from the PRISMA statement for reviews. ${ }^{14}$ Search criteria were first established, based on the stated objectives. Next, a search strategy was developed, and then implemented.

\section{Eligibility criteria}

Eligible studies were full peer-reviewed articles in English that presented original research investigating patient preferences for any aspect of either disease. For this research, the primary target was severe disease; however, in the absence of data for this category, it was considered acceptable if the majority of patients had at least moderate-to-severe disease. Severity could be categorized using any official definition, but preferably those of the GOLD ${ }^{13}$ (for COPD) and GINA ${ }^{12}$ (for asthma) investigators. Data reflecting mild disease were retained for comparative purposes. Excluded were articles dealing exclusively with smoking cessation or lung transplantation.

\section{Information sources}

We searched Medline and Embase from their inception to the end of November 2014. Retrieved articles and recent reviews were hand searched for further papers.

\section{Search and study selection}

Two researchers independently searched using the keywords "Pulmonary Disease, Chronic Obstructive", OR "asthma", AND "patient preference", "utilities", and combinations thereof. This process was done in iterations. In the first filtration, titles and abstracts were inspected; in the next, articles were retrieved, and the full text examined. Search outcomes were compared and differences resolved through consensus discussion.

\section{Data items}

Data extracted included the name of first author and the year of publication, countries in which the research was conducted, preferences analyzed (according to disease severity), and their outcomes. We were interested in preferences from a global perspective, and would accept any aspect that had been studied. Examples included preference for different approaches to care, aspects of treatment (methods of administration, devices, and drugs), effects or outcomes of treatments (symptoms, degree of control, side effects), levels of autonomy/dependence, choices (hospital versus hospice or homecare, the acceptance of invasive or noninvasive ventilation, cardiopulmonary resuscitation), or the willingness to pay (WTP) for drugs, devices, services or other aspects of care (cure, relief).

For analysis, COPD and asthma were generally reported separately, as they are separate diseases. Items assessed were separated by theme, then tabulated, and analyzed descriptively. No combination or quantitative summaries were planned. Themes included preferences for a) attributes of the disease and its management, b) patient autonomy/ decision making, c) location of care, d) end-of-life care management, e) different health states, f) specific products or devices, and g) treatment provided (satisfaction). 


\section{Results}

Figure 1 depicts the literature search results and disposition of identified articles. A total of 30 original research papers were included in this review; 25 articles ${ }^{15-39}$ assessed preference in COPD and five articles ${ }^{40-44}$ assessed preferences of patients having moderate-to-severe asthma. Of the 25 articles related to COPD, five assessed factors of care, three involved location of care, six determined preferences for specific products, one examined WTP, and ten examined end-of-life issues. Of the five articles related to asthma, one assessed patients' preference on decision making, two assessed patient preference of treatment, and two others assessed the WTP for asthmatic symptom levels.

In the Netherlands, more patients preferred early assisted discharge than those who preferred usual hospital or hospice care ${ }^{20}$ Furthermore, more patients preferred to die at home $(51.5 \%)$ than those who wished to die in a hospital (29.6\%) or in a hospice $(10.2 \%)$. However, the proportion of patients who wished to die at home dropped to $44.2 \%$ after 1 year. ${ }^{39}$ For issues related to end-of-life treatment, $96 \%$ of patients chose noninvasive ventilators (NIV); however, that figure dropped to $78 \%$ after seeing a photograph of a NIV..$^{28}$

Stavem et al reported an annual WTP of US\$24,096 for a cure for COPD with no side effects. ${ }^{38}$ In Canada, patients would pay $\$ 14.31$ per month for an additional symptom-free day. ${ }^{44}$ Meanwhile, a sample of the population in the United Kingdom would pay over $£ 160$ per month to have no morning symptoms, no nighttime awakenings, and no daytime symptoms. ${ }^{45}$ Lloyd et al assessed societal preferences for the avoidance of the symptoms associated with moderate-tosevere allergic asthma. While respondents placed the most value on avoidance of daytime symptoms, they also reported a higher WTP to avoid waking up in the night, and not requiring an inhaler compared to waking up with symptoms and requiring an inhaler. The authors acknowledged that this may not be intuitively correct, and postulated that the result may have been due to the respondents' not fully understanding the nature of inhaler use and its link with the severity of symptoms ${ }^{43}$ McTaggart-Cowan et al reported that patients with asthma preferred a treatment regimen that resulted in more symptom-free days but were willing to forego some of this benefit in exchange for a more convenient regimen or a reduction in the frequency of adverse events. ${ }^{44}$

Antonicelli et al assessed patient satisfaction with various treatments; however, the instrument assessing patient satisfaction had not been validated.$^{41}$ For COPD patients, Genuair $^{\circledR}$ was preferred over HandiHaler ${ }^{\circledR}, 22$ in addition Breezhaler ${ }^{\circledR}$ was also preferred over HandiHaler ${ }^{\circledR} .{ }^{23}$ Breezhaler $^{\circledR}$ was also preferred over Onbrez ${ }^{\circledR} .{ }^{25}$ In Canada, patients strongly preferred Respimat ${ }^{\circledR}$ over Turbuhaler ${ }^{\circledR}{ }^{42}$ Furthermore, COPD patients preferred using opioids due to significant relief from dyspnea. ${ }^{27}$

\section{Discussion}

Few studies have examined patient preference in COPD or asthma; the smallest number of such studies were in asthma patients. We found very little on patients with severe disease, which requires the most attention. Also, critically important is that both of these diseases can be fatal. Therefore, there is a pressing need for more studies on this topic.

A number of major themes and issues important to patients were elicited in these studies. Symptoms comprised a key concern as did their impact on daily life. Patients were willing to pay to have symptoms reduced or eliminated. Another recurring theme was the desire to have a positive and consistent relationship with their physician. They also expressed a strong wish to maintain autonomy, which meant being well informed and participating in decision making concerning their care. We also noted that different people had different preferences for modes of care and location, which need to be considered in their overall care plan. Finally, patients appeared to be generally satisfied with the care that they were receiving.

We noted that different attributes were ranked as "most preferred" or "most important" in each country. However, results may not be directly comparable between countries due to differences in the questions that were asked and the methods by which the responses were gathered, as well as differences in health care systems among the various countries. Since outcomes were heterogeneous, there was no opportunity to combine data. Carrying out subsequent studies that report similar outcomes could either refute or validate these results.

Absent from the retrieved studies was the measurement of patient preferences related to genetic testing or biomarkers when identifying risk factors of either COPD or asthma. While this technology may not yet be ready for clinical application, measuring patient preference around attributes related to genetic testing may inform public policy.

Preference related to exacerbations in asthma has been observed in two WTP studies. However, each study had limitations that may affect the rigor of the results. In the Lloyd et $\mathrm{al}^{43}$ study, it was unclear whether the sample size was sufficient to capture reliable estimates. Furthermore, a high proportion of participants failed the consistency check in the survey, rendering the sample even smaller. When the data were adjusted, WTP and utility results were deflated. It is possible that in the McTaggart-Cowan et al study, ${ }^{44}$ the 
Literature search: preferences from patients with moderate-to-severe COPD or asthma

\section{Databases searched}

- Embase 1980-2014 week 48

- Medline 1946 to November week 32014

Keywords

- Asthma

- Patient preference

- Pulmonary disease, chronic obstructive

- Satisfaction
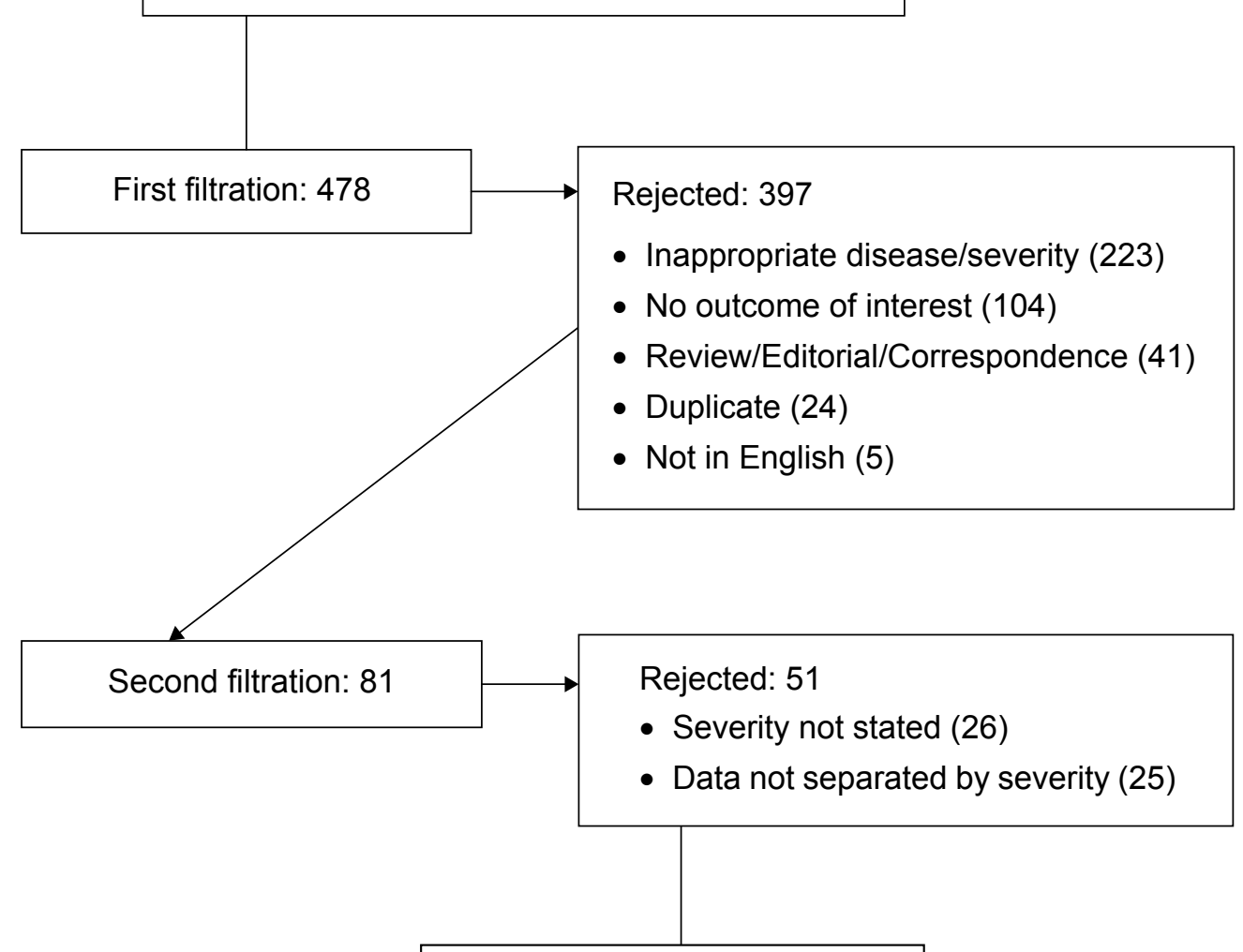

Final yield: 30 full text articles

On chronic obstructive pulmonary disease $=25$

On asthma $=5$

Figure I Literature search results. 
sample in the discrete choice experiment was also small, and not generalizable to the overall asthmatic population. Given these limitations, further studies measuring patient preference related to exacerbation in asthma are warranted.

\section{Limitations}

We searched only in the mainstream literature for articles; we did not examine the so-called "gray literature." It is possible that there are other published articles that we did not identify. We did not include studies that did not disaggregate data by severity level or reported the proportion of patients in each severity level. Some studies also used instruments that were not fully validated. Thus, the validity of their findings should be interpreted in that light. Besides, we examined only studies in English. There were only a few studies rejected for that reason, the impact of which is not known.

We did not locate any studies that examined preferences for modes of drug administration other than by inhalation.

The amount of studies located was quite small, suggesting that further research is needed to provide a more detailed picture of preferences. That is especially true for patients with severe disease (or worse).

We were unable to compare between diseases because there were few studies available and definitions for asthma were quite variable. There needs to be consensus on definitions used to appropriately define disease states.

\section{Conclusion}

The most important issues to patients with severe disease are symptom control, impact of disease on daily life, and positive relationship with the primary caregiver. Patients also strongly expressed that they wanted to be kept informed. The majority would accept CPR, nonmechanical or mechanical ventilation at end-of-life, and most preferred home to hospital.

Although the topic of patient preference is extremely important to both COPD and asthma patients, only a few studies have examined such issues. An opportunity therefore exists for researchers to explore these aspects of care in an attempt to develop improved methods and approaches. This finding is especially relevant for asthma, which can be reversed.

\section{Disclosure}

This research was sponsored by Janssen Pharmaceutica NV, Belgium. Basil G Bereza and Thomas R Einarson received consulting fees for conducting the research, and preparing the manuscript. Anders Troelsgaard Nielsen, Sverrir
Valgardsson, and Michiel EH Hemels are all employees of Janssen Cilag. The authors report no other conflicts of interest in this work.

\section{References}

1. Ferkol T, Schraufnagel D. The global burden of respiratory disease. Ann Am Thorac Soc. 2014;11:404-406.

2. Vos T, Flaxman AD, Naghavi M, et al. Years lived with disability (YLDs) for 1,160 sequelae of 289 diseases and injuries 1990-2010: a systematic analysis for the Global Burden of Disease Study 2010. Lancet. 2012;380:2163-2196.

3. Lozano R, Naghavi M, Foreman K, et al. Global and regional mortality from 235 causes of death for 20 age groups in 1990 and 2010 : a systematic analysis for the Global Burden of Disease Study 2010 Lancet. 2012;380:2095-2128.

4. Murray CJ, Vos T, Lozano R, et al. Disability-adjusted life years (DALYs) for 291 diseases and injuries in 21 regions, 1990-2010: a systematic analysis for the Global Burden of Disease Study 2010 Lancet. 2012;380:2197-2223.

5. NICE. Medicines Adherence: Involving Patients in Decisions about Prescribed Medicines and Supporting Adherence. NICE Clinical Guideline 76; 2009. Available from: http://www.nice.org.uk/guidance/ $\operatorname{cg} 76 /$ resources/guidance-medicines-adherence-pdf

6. Wennberg JE, Barry MJ, Fowler FJ, Mulley A. Outcomes research, PORTs, and health care reform. Ann N Y Acad Sci. 1993;703:52-62.

7. Torgerson DJ, Sibbald B. Understanding controlled trials. What is a patient preference trial? BMJ. 1998;316:360.

8. Brewin CR, Bradley C. Patient preferences and randomised clinical trials. BMJ. 1989;299:313-315.

9. Serra-Batlles J, Plaza V, Morejón E, Comella A, Brugués J. Costs of asthma according to the degree of severity. Eur Respir J. 1998;12:1322-1326.

10. Gonzalez-Barcala FJ, de la Fuente-Cid R, Tafalla M, Nuevo J, Caamaño-Isorna F. Factors associated with health-related quality of life in adults with asthma. A cross-sectional study. Multidiscip Respir Med. 2012;7:32.

11. Weldam SW, Lammers JW, Heijmans MJ, Schuurmans MJ. Perceived quality of life in chronic obstructive pulmonary disease patients: a cross-sectional study in primary care on the role of illness perceptions. BMC Fam Pract. 2014;14:140.

12. Global Initiative for Asthma. Global Strategy for Asthma Management and Prevention, 2010; 2010. Available from: www.ginasthma.org/pdf/ GINA_report_2010.pdf. [Updated 2012]. Accessed February 1, 2015.

13. Global Initiative for Chronic Obstructive Lung Disease. Pocket Guide to COPD Diagnosis, Management and Prevention, 2011;2011. Available from: http://www.goldcopd.org/uploads/users/files/GOLD_Pocket_ May2512.pdf. Accessed February 1, 2015.

14. Moher D, Liberati A, Tetzlaff J, Altman DG; PRISMA Group. Preferred reporting items for systematic reviews and meta-analyses: the PRISMA statement. PLoS Med. 2009;6:e1000097.

15. Bulcun E, Ekici M, Ekici A. Assessment of patients' preferences regarding the characteristics associated with the treatment of chronic obstructive pulmonary disease. Int J Chron Obstruct Pulmon Dis. 2014; 9:363-368.

16. Haughney J, Partridge MR, Vogelmeier C, et al. Exacerbations of COPD: quantifying the patient's perspective using discrete choice modelling. Eur Respir J. 2005;26:623-629.

17. Pisa G, Freytag S, Schandry R. Chronic obstructive pulmonary disease (COPD) patients' disease-related preferences: a study using conjoint analysis. Patient. 2013;6:93-101.

18. Rocker GM, Dodek PM, Heyland DK; Canadian Researchers at the End of Life Network. Toward optimal end-of-life care for patients with advanced chronic obstructive pulmonary disease: insights from a multicentre study. Can Respir J. 2008;15:249-254. 
19. Jordan P, Quadrelli S, Heres M, Belli L, Ruhl N, Colt H. Examining patients' preferences for participation in clinical decision-making: the experience in a Latin American chronic obstructive pulmonary disease and cancer outpatient population. Intern Med J. 2014;44:281-287.

20. Goossens LM, Utens CM, Smeenk FW, Donkers B, van Schayck OC, Rutten-van Mölken MP. Should I stay or should I go home? A latent class analysis of a discrete choice experiment on hospital-at-home. Value Health. 2014;17:588-596.

21. Utens CM, Goossens LM, van Schayck OC, et al. Patient preference and satisfaction in hospital-at-home and usual hospital care for COPD exacerbations: results of a randomised controlled trial. Int J Nurs Stud. 2013;50:1537-1549.

22. Beier J, Kirsten AM, Mróz R, et al. Efficacy and safety of aclidinium bromide compared with placebo and tiotropium in patients with moderate-to-severe chronic obstructive pulmonary disease: results from a 6-week, randomized, controlled Phase IIIb study. COPD. 2013;10: 511-522.

23. Chapman KR, Fogarty CM, Peckitt C, et al. Delivery characteristics and patients' handling of two single-dose dry-powder inhalers used in COPD. Int J Chron Obstruct Pulmon Dis. 2011;6:353-363.

24. Ferguson GT, Ghafouri M, Dai L, Dunn LJ. COPD patient satisfaction with ipratropium bromide/albuterol delivered via Respimat: a randomized, controlled study. Int J Chron Obstruct Pulmon Dis. 2013;8: 139-150.

25. Ohno T, Wada S, Hanada S, Sawaguchi H, Muraki M, Tohda Y. Efficacy of indacaterol on quality of life and pulmonary function in patients with COPD and inhaler device preferences. Int J Chron Obstruct Pulmon Dis. 2014;9:107-114.

26. Van Der Palen J, Ginko T, Kroker A, et al. Preference, satisfaction and errors with two dry powder inhalers in patients with COPD. Expert Opin Drug Deliv. 2013;10:1023-1031.

27. Rocker GM, Simpson AC, Joanne Young BHSC, et al. Opioid therapy for refractory dyspnea in patients with advanced chronic obstructive pulmonary disease: patients' experiences and outcomes. CMAJOpen. 2013; 1:E27-E36.

28. Chakrabarti B, Sulaiman MI, Davies L, Calverley PM, Warburton CJ, Angus RM. A study of patient attitudes in the United Kingdom toward ventilatory support in chronic obstructive pulmonary disease. J Palliat Med. 2009;12:1029-1035.

29. Dales RE, O'Connor A, Hebert P, Sullivan K, McKim D, LlewellynThomas H. Intubation and mechanical ventilation for COPD: development of an instrument to elicit patient preferences. Chest. 1999;116: 792-800.

30. Downey L, Au DH, Curtis JR, Engelberg RA. Life-sustaining treatment preferences: matches and mismatches between patients' preferences and clinicians' perceptions. J Pain Symptom Manage. 2013; 46:9-19.

31. Gaber KA, Barnett M, Planchant Y, McGavin CR. Attitudes of 100 patients with chronic obstructive pulmonary disease to artificial ventilation and cardiopulmonary resuscitation. Palliat Med. 2004; $18: 626-629$
32. Janssen DJ, Spruit MA, Schols JM, et al. Predicting changes in preferences for life-sustaining treatment among patients with advanced chronic organ failure. Chest. 2012;141:1251-1259.

33. Norris WM, Nielsen EL, Engelberg RA, Curtis JR. Treatment preferences for resuscitation and critical care among homeless persons. Chest. 2005;127:2180-2187.

34. Reinke LF, Slatore CG, Udris EM, Moss BR, Johnson EA, Au DH. The association of depression and preferences for life-sustaining treatments in veterans with chronic obstructive pulmonary disease. J Pain Symptom Manage. 2011;41:402-411.

35. Stapleton RD, Nielsen EL, Engelberg RA, Patrick DL, Curtis JR. Association of depression and life-sustaining treatment preferences in patients with COPD. Chest. 2005;127:328-334.

36. Travaline JM, Silverman HJ. Discussions with outpatients with chronic obstructive pulmonary disease regarding mechanical ventilation as life-sustaining therapy. South Med J. 1995;88:1034-1038.

37. Wilson KG, Aaron SD, Vandemheen KL, et al. Evaluation of a decision aid for making choices about intubation and mechanical ventilation in chronic obstructive pulmonary disease. Patient Educ Couns. 2005;57: $88-95$.

38. Stavem K. Association of willingness to pay with severity of chronic obstructive pulmonary disease, health status and other preference measures. Int J Tuberc Lung Dis. 2002;6:542-549.

39. Janssen DJ, Spruit MA, Schols JM, Wouters EF. Dynamic preferences for site of death among patients with advanced chronic obstructive pulmonary disease, chronic heart failure, or chronic renal failure. $J$ Pain Symptom Manage. 2013;46:826-836.

40. Adams RJ, Smith BJ, Ruffin RE. Patient preferences for autonomy in decision making asthma management. Thorax. 2001;56:126-132.

41. Antonicelli L, Bucca C, Neri M, et al. Asthma severity and medical resource utilisation. Eur Respir J. 2004;23:723-729.

42. Hodder R, Reese PR, Slaton T. Asthma patients prefer Respimat Soft Mist Inhaler to Turbuhaler. Int J Chron Obstruct Pulmon Dis. 2009;4:225-232.

43. Lloyd A, Doyle S, Dewilde S, Turk F. Preferences and utilities for the symptoms of moderate to severe allergic asthma. Eur J Health Econ. 2008;9:275-284.

44. McTaggart-Cowan HM, Shi P, Fitzgerald JM, et al. An evaluation of patients' willingness to trade symptom-free days for asthma related treatment risks: a discrete choice experiment. J Asthma. 2008;45: 630-638.

45. Lloyd A, McIntosh E, Williams AE, Kaptein A, Rabe KF. How does patients' quality of life guide their preferences regarding aspects of asthma therapy?: a patient-preference study using discrete-choice experiment methodology. Patient. 2008;1:309-316.
International Journal of COPD

\section{Publish your work in this journal}

The International Journal of COPD is an international, peer-reviewed journal of therapeutics and pharmacology focusing on concise rapid reporting of clinical studies and reviews in COPD. Special focus is given to the pathophysiological processes underlying the disease, intervention programs, patient focused education, and self management protocols.

\section{Dovepress}

This journal is indexed on PubMed Central, MedLine and CAS. The manuscript management system is completely online and includes a very quick and fair peer-review system, which is all easy to use. Visit http://www.dovepress.com/testimonials.php to read real quotes from published authors. 